Proceedings

\title{
Plug-and-Play Solutions for Energy-Efficiency Deep Renovation of European Building Stock ${ }^{+}$
}

\author{
Rizal Sebastian 1,*, Anna Gralka 1, Rosamaria Olivadese 1, Marco Arnesano 2, Gian Marco Revel 2, \\ Timo Hartmann ${ }^{3}$ and Christoph Gutsche ${ }^{3}$ \\ 1 DEMO Consultants BV, Delftechpark 10, 2628XH Delft, The Netherlands; anna@demobv.nl (A.G.); \\ rosamaria@demobv.nl (R.O.) \\ 2 Department of Industrial Engineering and Mathematical Sciences, Università Politecnica delle Marche, via \\ Brecce Bianche 12, 60131 Ancona, Italy; m.arnesano@univpm.it (M.A.); gm.revel@univpm.it (G.M.R.) \\ 3 Department of Civil and Building Systems, Technische Universität Berlin, Gustav-Meyer-Allee 25, 13355 \\ Berlin, Germany; timo.hartmann@tu-berlin.de (T.H.); christoph.gutsche@tu-berlin.de (C.G.) \\ * Correspondence: rizal_sebastian@skpnet.nl; Tel.: +31-6-18986913 \\ + Presented at the Sustainable Places 2018 (SP 2018), Aix-Les-Bains, France, 27-29 June 2018.
}

Published: 25 September 2018

\begin{abstract}
Ninety percent of the existing building stock in Europe was built before 1990. These buildings are in urgent need for a significant improvement of energy-efficiency through renovation. State-of-the-art renovation solutions are available, but costly and lengthy renovation processes and incomprehensible technical complexities hinder the achievement of a wide impact at a European scale. This paper presents a research on Plug-and-Play (PnP) technologies supported by Building Information Modelling (BIM) to provide affordable, interchangeable and quick-installation solutions to overcome the main barriers of building deep renovation.
\end{abstract}

Keywords: energy-efficient buildings; deep renovation; Plug-and-Play (PnP); Building Information Modelling (BIM); Building Energy Modelling (BEM)

\section{Introduction}

Ninety percent of the existing building stock in Europe was built before 1990 and have reached the age for renovation. There is an urgent need for a significant improvement of energy efficiency through renovation. The existing building stock is the single biggest potential sector for energy saving since buildings account for $40 \%$ of the EU's energy consumption, $36 \%$ of its $\mathrm{CO}_{2}$ emissions, and $55 \%$ of its electricity consumption. Previous studies have summarized the financial, technical, process, regulatory, and awareness barriers to deep renovation [1,2]. The financial barriers are concerned with high upfront costs of renovation; long payback for the key measures; and limited access to finance due to lack of standard approaches for investment in energy performance improvements. The technical barriers are: lack of technical solutions for specific building typologies and high complexity of renovation projects. The process barriers are mainly due to fragmentation of the supply chain since there is a lack of single parties willing to offer integrated deep renovation or near zero energy renovation as a service. Certain technical barriers are caused by the complexity of renovation and the burden for home owners to contract various parties (architects, energy advisors, contractors, etc.) for each type of the specialized work. The main parts of the regulatory barriers are due to varying requirements and national guidelines in the EU member states that address Energy Performance Co-efficient (EPC) and Energy Performance of Buildings Directive (EPBD). Next to the previous barriers, awareness barriers still exist since most building occupants are insufficiently acquainted with the energy performance aspects of their buildings and the potential increase in comfort and quality of life that deep renovation can bring. 
The objective of the research presented in this paper is to break through the barriers of deep renovation and to promote innovative solutions with a high replicability potential at European scale. This paper refers to the EU collaborative research project titled P2Endure, which is focused on practical development and implementation of Plug-and-Play (PnP) solutions and tools for deep renovation of residential and public buildings [3]. The following section of this paper is a brief theoretical discussion on the PnP concept, its origin and its adaptation and adoption for buildings. Subsequently, the research methodology in the P2Endure project is explained, and the preliminary research findings are analyzed. Accordingly, conclusions are drawn on how PnP solutions can break through the current barriers for deep renovation. Finally, recommendations are presented on the roles of PnP solutions for upgrading the smartness of existing buildings through deep renovation and future updates.

\section{Theoretical Review}

The term Plug-and-Play (PnP) was coined for the first time in 1995 when the principal founder and the then chairman of Microsoft Corporation, Bill Gates released the new Microsoft Windows 95. He presented, among others, the PnP capabilities of the new computer operating system, which made it easy to install hardware and software [4].

In more than two decades after its introduction, the term "Plug-and-Play" has been widely used beyond the domain of computer science, including in construction. Such solutions address several key characteristics of the PnP concept, namely: typical functionality, modularity, and dry joints between different components. Furthermore, reduced human intervention, as an essential part of the $\mathrm{PnP}$ concept, was realized by shifting from on-site manual labor to off-site manufacturing. Beyond standardization and fast on-site assembly, user-friendliness as the ultimate aspect of $\mathrm{PnP}$ is addressed by the state-of-the-art solutions for prefab and modular construction through the assembly techniques using simple joints without heavy equipment. User-friendly PnP solutions thus answer to the need to cope with significantly lower number of workers and to minimize manual effort on the construction site. The user-friendliness of certain PnP solutions even allows non-professional end-users to choose and install interior components and room units [5].

The PnP solutions continue to progress in achieving the three key functionalities of smartness in buildings as defined in the revised EU EPBD, i.e., (1) the ability to optimize their energy performance; (2) the ability to adapt their operational modes in response to the needs of the building occupants; and (3) the flexibility of the overall building systems in relation to the surrounding environments or energy grid [6].

Smart PnP components are usually integrated with Building Automation and Control Systems (BACS) or Building Management Systems (BMS). The roles of information management and data interoperability have become significant in relation to the PnP concept. Building Information Modelling (BIM) grows rapidly and it is needed throughout the whole value chain of PnP solutions. The importance of BIM for deep renovation of prefab component based buildings has been underlined in previous studies [7]. Considering the important role of BIM, the research presented in this paper builds upon the state-of-the-art knowledge to investigate and demonstrate BIM-based Plug-and-Play solutions for deep renovation.

\section{Research Methodology}

This paper presents the technical research within the European collaborative project titled P2Endure with a 4-year duration [3]. The project started with a selection of state-of-the-art PnP renovation solutions, which are either on the market or available as prototypes from previous research projects. These solutions were categorized in three groups: (1) PnP components for building envelopes; (2) PnP retrofit for MEP/HVAC systems; and (3) on-site 3D technologies

Next to the renovation solutions, a methodology for cost-effective and time-efficient deep renovation is proposed. The methodology, called the $4 \mathrm{M}$ process, consists of four main stages, namely: Mapping, Modelling, Making and Monitoring. The "Mapping" process comprises 3D laser and thermal scanning accompanied by condition assessment of the existing buildings, a review of 
the energy consumption records in the preceding years, and an analysis of the Indoor Environment Quality (IEQ) before renovation. The "Modelling" uses As-Built Building Information Models (As-Built BIM) as input for BIM-based renovation designing and Building Energy Modelling (BEM) for simulating the performance of viable renovation measures. The "Making" process takes place both off-site and on-site. BIM is used for product engineering and in support of off-site prefabrication. In certain cases, BIM is used for on-site 3D printing with collaborative robotics. Finally, the "Monitoring" process is conducted for energy and comfort.

P2Endure also optimizes and deploys supporting ICT tools for deep renovation, in particular: a BIM Parametric Modeler, a software application for building inspection using mobile devices, and a lifecycle cost (LCC) management tool. The BIM Parametric Modeler is used to configure and analyze renovation options by estimating the energy performance impacts of individual and combined renovation measures. The building inspection software assists the building specialists during visual/non-intrusive inspection to register the maintenance condition of building and MEP/HVAC components.

Empirical evidence of the effectiveness of P2Endure solutions is gathered from the implementation of 10 deep renovation projects in various EU countries. These real demonstration cases represent the main typologies within the existing building stock in Europe subjected for deep renovation, namely: apartment complexes and low-rise residential districts, nurseries and educational facilities, and historic buildings.

\section{Actual Research Findings}

The first outcome from the "Mapping" stage is based on the '3D scan to BIM' process, which started with collecting existing as-built documentation of the building, such as drawings and specifications. Analysis of the available information was used to define the most optimal protocol for 3D data acquisition through laser scanning. As such, the 3D point cloud models resulting from laser scanning could complement the information from the available as-built documentation. The 3D point cloud models were used as reference models to create BIM. Next to laser scans, thermal scans were also performed on the existing buildings to detect thermal-related issues which compromised the buildings' energy performance. The As-Built BIM models were imported into the software tool for building condition assessment [8]. This software generated a decomposition list of the building components, which was used to assign the condition score to each component based on a visual inspection. The condition scores were then taken into consideration whether certain building parts should be maintained, repaired, refurbished or replaced depending on the selected renovation options.

The "Modelling" stage has delivered preliminary BIM of renovation designs along with their energy performance estimates, which were calculated through Building Energy Modelling (BEM). The BIM Parametric Modeler tool imported an As-Built BEM model in .idf format derived from EnergyPlus (read explanation in the next paragraph) and used this model to make configurations of suitable renovation solutions and to present the impact of various renovation options [9].

P2Endure tested several methods for 'BIM to BEM' since there was still no commonly accepted and fully-reliable method for BIM-based energy simulation [10]. The first 'BIM to BEM' method included the following steps: (1) Simplified BIM in AutoDesk Revit format; (2) Export to idf; (3) model modification and energy modelling using Google SketchUp with Legacy Open Studio; (4) Export to .idf; (5) energy simulation using EnergyPlus; (6) calculation validation. The second method relied on IFC open standard for BIM, and the process went as follows: (1) Simplified BIM in AutoDesk Revit format; (2) Export to .ifc; (3) model modification using IFC Builder; (4) energy modelling using CYPETHERM LOAD and CYPETHERM HVAC; (5) energy simulation using EnergyPlus; (6) calculation validation.

The preliminary outcomes of the third stage in the $4 \mathrm{M}$ process methodology, the "Making", are the following: lightweight multifunctional panels for façade retrofit; reversible windows with an optimized design and a scaled-up prefabrication process; rooftop retrofit modules based on lightweight steel structures; and on-site 3D printing of façade layers using collaborative robotics 
[11]. The multifunctional panels were produced by Fermacell in Germany where a set of full-scale mock-ups for P2Endure were developed and examined. At the deep renovation case in Warsaw, Poland, BIM was used to create the modules for the panel.

The reversible windows in P2Endure were developed by BG TEC in Poland [11]. These windows have dual thermal properties to keep the warmth inside the building in winter time, or to reflect the solar radiation and accommodate fresh air to the building during summer. Another PnP product, rooftop retrofit system, was designed by PANPlus in the Netherlands. Rooftop retrofit has a substantial contribution in terms of energy saving, especially for existing buildings without adequate roof insulations. PnP solutions in P2Endure also include on-site 3D printing for deep renovation as developed by Robot-At-Work and Invela from Denmark. 3D printing is done with collaborative robotics, which includes high-precision façade rendering or plastering by coating the exterior wall with materials to level the surface, and robot assisted milling that allows for three dimensional designs.

"Monitoring" as the final stage in the 4M process methodology in P2Endure has not yet delivered results as the renovation projects are still ongoing. Regarding IEQ, monitoring activities have commenced with the installation and calibration of the Comfort Eye tool. In addition to IEQ information, the Comfort Eye tool can provide complementary information about the building envelope performance.

\section{Conclusions and Discussions}

This research paper investigates and demonstrates Plug-and-Play (PnP) concept and solutions for building deep renovation. Based on the empirical findings from the P2Endure research project, it concludes that PnP solutions can break through the barriers to renovate the existing building stock in Europe. The financial barriers can be resolved by affordable PnP renovation solutions which are produced in a large volume. Cost saving will also be achieved by using simple and universal joints during on-site assembly, so the PnP solutions do not need tailor-made techniques for each renovation project. Another contribution to resolve the financial barriers is found in easier and more reliable calculation of Return on Investment (RoI) of the PnP solutions since their performance levels are standardized. Standard PnP installation procedures will, in turn, resolve the technical barriers in terms of renovation project planning and construction skills. The process barriers in the renovation supply-chain will be broken since the market will become more open as PnP solutions imply that substitute products and services are available so dependency on a single party is minimized. The regulatory barriers due to non-uniformity of definitions and performance target can be resolved especially by smart PnP renovation solutions that meet the standard definition of smart buildings and Smart Readiness Indicators (SRI) included in the revised EPBD. Finally, the awareness barriers can be removed as the building occupants have become familiar with the PnP concept thanks to advancements in ICT and home appliances.

The P2Endure's 4M methodology is useful to clarify the PnP approach throughout the whole deep renovation process. There remain several bottlenecks of PnP deep renovation. Although integration and interoperability are in the essence of PnP concept, certain limitations still exist in all 4Ms. Towards the future, PnP deep renovation based on P2Endure research methodology is important to upgrade the smartness of the existing building stock in Europe. In P2Endure, upgrading the buildings' smartness has begun by digitization of building and energy information through BIM and BEM. Follow-up research should be dedicated to automation and standardization of procedures and tools to reduce time and to increase accuracy in As-Built BIM creation and BEM simulation. Furthermore, smart/advanced materials should be used for on-site 3D printing. The PnP renovation components, such multifunctional panels and reversible windows should be made smart as well through integration of smart sensing, actuator and control systems. Smart monitoring after renovation which covers various aspects, i.e., energy performance, health and comfort, and lifecycle cost, should continuously be upgraded, too. 
Author Contributions: Conceptualization, R.S.; Methodology, R.S., A.G., R.O., M.A., G.M.R., T.H., and C.G.; Investigation, R.S., A.G., R.O., M.A., G.M.R., T.H., and C.G.; Resources, R.S., R.O., MA., and C.G.; Writing-Original Draft Preparation, R.S., A.G., and R.O., and C.G.; Writing-Review \& Editing, R.S., A.G., R.O., M.A., G.M.R., T.H., and C.G.; Funding Acquisition, R.S.

Funding: This research was funded by the European Union's Horizon 2020 research and innovation program grant number 723391.

Conflicts of Interest: The authors declare no conflicts of interest.

\section{References}

1. Artola, I.; Rademaekers, K.; Williams, R.; Yearwood, J. Boosting Building Renovation: What Potential and Value for Europe? European Parliament: Brussels, Belgium, 2016.

2. Economidou, M. Europe's Buildings under the Microscope: A Country-by-Country Review of the Energy Performance of Buildings; BPIE: Brussels, Belgium, 2011.

3. P2Endure: Plug-and-Play Product and Process Innovation for Building Deep Renovation. Available online: https://www.P2Endure-project.eu (accessed on 25 July 2018).

4. Forant, N. The History of Microsoft Windows First 25 Years. Available online: https://www.sobxtech.com/history-of-windows/ (accessed on 23 July 2018).

5. Sebastian, R.; Nieuwenhuijzen, E.J. Quick Scan Flexible Building for Solids; TNO: Delft, The Netherlands, 2007.

6. Moseley, P. EU support for innovation and market uptake in smart buildings under the Horizon 2020 Framework Programme. Buildings 2017, 7, 105-129.

7. BPIE. Prefabricated Systems for Deep Energy Retrofits of Residential Buildings. Available online: http://bpie.eu/wp-content/uploads/2016/02/Deep-dive-1-Prefab-systems.pdf (accessed on 27 July 2018).

8. P2Endure. Mobile Inspection Tool for Building Condition Assessment; Deliverable Report D2.3; Report; 2017.

9. P2Endure. BIM Parametric Modeler; Deliverable Report D2.2; Report; 2017.

10. Farzaneh, A.; Carriere, J.; Forgues, D.; Monfet, D. Framework for Using Building Information Modeling to Create a Building Energy Model. J. Archit. Eng. 2018, 24, 05018001.

11. P2Endure. Sets of PnP Prefab Components for Building Envelopes; Deliverable Report D1.1; Report; 2017.

(C) 2018 by the authors. Licensee MDPI, Basel, Switzerland. This article is an open access article distributed under the terms and conditions of the Creative Commons Attribution (CC BY) license (http://creativecommons.org/licenses/by/4.0/). 